\title{
Biomaterials for Periodontal Regeneration: A Comprehensive Discussion of its Merits and Demerits
}

\author{
Manju Natarajan* \\ BDS, MS - Master of Science in Health Sciences, Merrimack College, Massachusetts, USA \\ ${ }^{*}$ Correspondence author: Dr. Manju Natarajan B.D.S, M.S - Master of Science in Health Science, Merrimack College, Massachusetts, USA; \\ E-mail: manju.parthiban@gmail.com
}

Received: October 06, 2018; Accepted: October 13, 2018; Published: October 14, 2018;

\begin{abstract}
Treatment of periodontal diseases is becoming more prevalent and one of the treatment methods is to regenerate periodontal tissues. Over the period many biomaterials have been developed many of which are currently being used and more research is still in progress. Such a range of biomaterials choice makes it a challenging ordeal for Dentists to weigh the pros and cons of the popular biomaterials. This manuscript attempts to be a comprehensive document that discusses the merits and demerits of various biomaterials to aid in the decision making of biomaterial choice for periodontal disease treatments.
\end{abstract}

Key words: Dental Biomaterials, Periodontal Disease Biomaterials, Biomaterials for Intra-bony Defects.

\section{Introduction}

Periodontal diseases are one of the common dental problems among adults in the US population. According to the American Academy of Periodontology (AAP) it is defined as a chronic inflammatory disease that affects the gum tissue and bone supporting the teeth. $47.2 \%$ of adults aged 30 years and older have some form of periodontal disease and it increases with age, $70.1 \%$ of adults 65 years and older have periodontal disease [1]. It's well known that if not treated, it will lead to dental (tooth loss due to alveolar bone destruction) and medical complications (heart diseases ,aggravate/ worsen existing systemic conditions like diabetes by raising its Hbalc level due to entry of oral bacteria in to blood stream). So, it is inevitable to treat periodontal diseases and there are many treatment modalities available depending on the nature of bone destruction and symptoms of periodontal diseases. This paper will specifically explore the biomaterials emerging and being used to regenerate periodontal tissue as one of the treatment options.

\section{Calcium Phosphate}

Advantages of Calcium phosphate- it has a similar composition to bone mineral. It will promote cellular function and has a bioactivity meaning it will form the bone like material when used for regeneration. As CP has a high affinity for proteins, it will act as ideal carriers for peptides, bone growth factors etc. So, once it is bonded with circulating bone morphogenic proteins, it will promote osteo-induction [2]. Also has osteo-conductive property [3]. All these properties combined make this material more suitable for tissue regeneration and it could be used in gene therapy, cancer therapy and osteoporosis therapy. There are no known adverse effects associated with using material.

\section{Hydroxyapatite (HA)}

Advantages - Like calcium phosphate, HP also has a similar composition to natural bone mineral [4]. When it is implanted, it chemically bonds to bone [5]. The biocompatibility, tolerance and biologically active property of HA makes it ideal material for bone substitutes [6]. Disadvantages - it is long term outcome is not ideal as it has inconsistent cell reactions which limits its application in clinic [7]. A variant of HA called nano-HA has good biocompatibility, increases protein synthesis of PDL cells, improves alkaline phosphatase activity, induces cell differentiation, promotes periodontal tissue regeneration and forms new teeth attachments [8]. But the only disadvantage is limited bone regeneration (Li Shue, Biomaterials for periodontal regeneration: A review of ceramics and polymers, 2012) [3].

\section{Tri Calcium Phosphate (TCP)}

Advantages - It has been used for the past few years after thoroughly investigated as a bone substitute. The two crystallographic forms of TCP include; Alpha TCP, Beta TCP. Beta TCP shows the characteristics of good biocompatibility and osteo-conductivity [9]. When it comes to bone regeneration potential, $\beta$-TCP grafts have been shown to be like autogenous bone, FDBA, DFDBA and collagen sponge [10]. It can be used to repair periapical and marginal periodontal defects, as well as alveolar bony defects [10] however; some studies in the literature suggest that $\beta$-TCP could also be utilized for alveolar ridge augmentation in vertical and horizontal dimensions with variable results. Although it produces substantial clinical improvements in treating intra bony defects, it does not seem to regenerate cementum, PDL or bone (disadvantage) [11]. 


\section{Calcium Polyphosphate (CPP)}

Advantages - Calcium-Polyphosphate (CPP) is another good bone substitute as the mechanical properties are like trabecular bone. It has controlled degradability which is essential in tissue regeneration and El Sayegh et al. demonstrated that the degradation rate of CPP did not substantially affect the interactions of human gingival fibroblasts compared with titanium alloy substrates. CPP shows very good integration to host bone when implanted in vivo [12]. According to Nelson et al. CPP has a good bone regeneration potential after finding its ability to repair canine mandibular alveolar defects.

\section{Brushite (Di Calcium Phosphate Dihydrate (DCPP))}

Advantages - it has been shown that injectable brushite has the capability of regenerating bone. Potential applications of this material include vertical bone augmentation, buccal dehiscence defects. The only disadvantage associated with using brushite bone grafts is that after implantation, it will convert to HA which would limit its resorption rate. To overcome this advantage, a variant of Brushite called Monetite which will not convert to HA. By doing so, the resorption rate of Monetite is higher than Brushite [9].

\section{Bioactive glass (BG)}

Advantages - BG graft materials usually contain silicon dioxide, calcium oxide, sodium oxide, and phosphorus pentoxide. Studies have demonstrated that bioactive glass could induce bone formation as it enhances the expression of type I collagen, osteocalcin and alkaline phosphatase gene expression and osteocalcin protein [13]. Bioactive glass nanoparticles have been shown to induce cementoblasts to proliferate in an in vivo study [14]. BG grafts can be used as a supplement when the mount of the harvested autogenous grafts is not sufficient [15]. According to Mengel et all, BG produced a significant improvement in the parameters $\mathrm{PD}, \mathrm{CAL}$ and distance from alveolar crest to defect base [16]. The disadvantage is that it has limited regenerative outcomes based on Nevins et all who conducted histological analysis [17].

\section{Calcium Sulphate}

Advantages - CS is used as a barrier material and it has greater compressive strength than cancellous bone and will resorb in 5-\& 7 weeks [18]. It inhibits the epithelial and connective tissue ingrowth to produce a predictable regenerative response [19]. CS easily adapts and adheres to the root surface, including root concavities [20]. In addition, CS is readily available, it can be easily sterilized, inexpensive (economic alternative to collagen), completely resorbable, and biocompatible, and in the presence of bone and periosteum, it becomes osteogenic [21]. No specific disadvantages have been found when this material was used.

\section{Enamel Matrix Protein}

Enamel Matrix proteins consist of three primary proteins which are similar to amelogenin, enamelin and sheathaline respectively with two enzymes and it is derived from porcine teeth. A wide range of in vitro and in vivo studies have demonstrated that EMD and amelogenins stimulate growth of multiple mesenchymal cell types including fibroblasts, cementoblasts, osteoblasts, and stem cells [22]. In addition, it inhibits epithelial downgrowth. Although there are some controversies around using this EMP, some studies stated that it helps to repair bony defects in advanced intra bony defects. Recently, American Academy of Periodontology concluded that EMD is generally comparable with demineralized freeze-dried bone allograft and GTR in improving clinical parameters in the treatment of intra bony defects (Zeeshan Sheikh, Natural graft tissues and synthetic biomaterials for periodontal and alveolar bone reconstructive applications: a review, 2017) [9].

\section{Platelet Rich Plasma and Platelet Rich fibrin}

As these both (PRP \& PRF) contains high platelets concentrate, these two play a role in augmentation of tissue healing, antimicrobial activity, modification of host defense mechanisms and immune reaction. The potential benefits of PRP is not consistent in the literature review because some authors reported significant improvements in tissue healing and bone formation using PRP $[23,24]$. others failed to observe improvement $[25,26]$. The technical and regenerative limitations of PRP restrict its applications. On the other hand, PRF has many advantages; completely autogenous, extended growth factor release for 7 days, simple and faster technique, in-expensive, no requirement of any additive constituent such as bovine thrombin, no biochemical handling involved no associated immune reactions and no associated infections [27]. The limitation of PRF is that a dried glass tube or glass coated plastic tube should be used. In addition, quantity and quality of PRF with aging, influence of systemic diseases such as thrombocytopenia, bleeding disorders etc, nutrition, blood profile, autoimmunity and genetic predisposition may influence the nature of PRF but not confirmed yet [27].

\section{References}

1. CDC (2015) Center for Disease Control and Prevention. Retrieved from What is Periodontal Disease?: https://www.cdc.gov/oralhealth/periodontal disease/index. htm

2. Racquel Z, LeGeros JP (2006) Calcium Phosphate Biomaterials: An Update. International Journal of Oral Medicine and Science 4: 117-123.

3. Shue L, Yufeng Z, Mony U (2012) Biomaterials for periodontal regeneration: a review of ceramics and polymers. Biomatter 2: 271-277. [crossref]

4. Wang H, Li Y, Zuo Y, Li J, Ma S, et al. (2007) Biocompatibility and osteogenesis of biomimetic nano-hydroxyapatite/polyamide composite scaffolds for bone tissue engineering. Biomaterials 28: 3338-3348. [crossref]

5. Bagambisa FB, Joos U, Schilli W (1993) Mechanisms and structure of the bond between bone and hydroxyapatite ceramics. J Biomed Mater Res 27: 1047-1055. [crossref]

6. Sanjay Gupta, Vandana KL (2013) Evaluation of hydroxyapatite (Periobone-G) as a bone graft material and calcium sulfate barrier (Capset) in treatment of interproximal vertical defects: A clinical and radiologic study. Journal of Indian Society of Periodontology 17: 96-103.

7. Deligianni DD, Katsala ND, Koutsoukos PG, Missirlis YF (2001) Effect of surface roughness of hydroxyapatite on human bone marrow cell adhesion, proliferation, differentiation and detachment strength. Biomaterials 22: 87-96. [crossref]

8. Yancong Zhang, Hanwen Sun, Xinfeng Song, Xiangling Gu, Chunyan Sun (2015) Biomaterials for Periodontal Tissue Regeneration. Review of Advanced Materical Journal 209-214.

9. Sheikh Z, Hamdan N, Ikeda Y, Grynpas M, Ganss B, et al. (2017) Natural graft tissues and synthetic biomaterials for periodontal and alveolar bone reconstructive applications: a review. Biomaterials Research 21: 9. [crossref]

10. Nakajima Y, Fiorellini JP, Kim DM, Weber HP (2007) Regeneration of standardized mandibular bone defects using expanded polytetrafluoroethylene membrane and various bone fillers. International Journal of Periodontics and Restorative Dentistry 27: 151-159. [crossref] 
11. Stavropoulos A, Windisch P, Szendröi-Kiss D, Peter R, Gera I, et al. (2010) Clinical and histologic evaluation of granular Beta-tricalcium phosphate for the treatment of human intrabony periodontal defects: a report on five cases. Journal of Periodontology 81: 325-332. [crossref]

12. Grynpas MD, Pilliar RM, Kandel RA, Renlund R, Filiaggi M, et al. (2002) Porous calcium polyphosphate scaffolds for bone substitute applications in vivo studies. Biomaterials Journal 23: 2063-2070. [crossref]

13. Varanasi VG, Owyoung JB, Saiz E, Marshall SJ, Marshall GW, et al. (2011) The ionic products of bioactive glass particle dissolution enhance periodontal ligament fibroblast osteocalcin expression and enhance early mineralized tissue development. J Biomed Mater Res A 98: 177-184. [crossref]

14. Carvalho SM, Oliveira AA, Jardim CA, Melo CB, Gomes DA, et al. (2012) Characterization and induction of cementoblast cell proliferation by bioactive glass nanoparticles. Journal of Tissue Engineering and Regenerative Medicine 6: 813-821. [crossref]

15. Yadav VS, Narula SC, Sharma RK, Tewari S, Yadav R (2011) Clinical evaluation of guided tissue regeneration combined with autogenous bone or autogenous bone mixed with bioactive glass in intrabony defects. J Oral Sci 53: 481-488. [crossref]

16. Mengel R, Soffner M, Flores-de-Jacoby L (2003) Bioabsorbable membrane and bioactive glass in the treatment of intrabony defects in patients with generalized aggressive periodontitis: results of a 12-month clinical and radiological study. Journal of Periodontology 74: 899-908. [crossref]

17. Nevins ML, Camelo M, Nevins M, King CJ, Oringer RJ, et al. (2000) Human histologic evaluation of bioactive ceramic in the treatment of periodontal osseous defects. The International Journal of Periodontics and Restorative Dentistry 20: 458-467. [crossref]

18. Sukumar S, Drízhal I, Paulusová V, Bukac J (2011) Surgical treatment of periodontal intrabony defects with calcium sulphate in combination with betatricalcium phosphate: clinical observations two years post-surgery. Acta Medica 54: 13-20. [crossref]
19. Sottosanti J (1992) Calcium sulfate: a biodegradable and biocompatible barrier for guided tissue regeneration. Compendium 13: 226-228. [crossref]

20. Anson D (1996) Calcium sulfate: a 4-year observation of its use as a resorbable barrier in guided tissue regeneration of periodontal defects. Compendium of Continuing Education in Dentistry 17: 895-899. [crossref]

21. Shilpa Budhiraja, Neeta Bhavsar, Santosh Kumar, Khushboo Desai, Sareen Duseja (2012) Evaluation of calcium sulphate barrier to collagen membrane in intrabony defects. Journal of Periodontal and Implant Science 42: 237-242.

22. Rathva VJ (2011) Enamel matrix protein derivatives: role in periodontal regeneration. Clinical Cosmetic and Investigational Dentistry 3: 79-92. [crossref]

23. Sánchez AR, Sheridan PJ, Kupp LI (2003) Is platelet-rich plasma the perfect enhancement factor? A current review. The International Journal of Oral and Maxillofacial Impants 18: 93-103. [crossref]

24. Ross R, Glomset J, Kariya B, Harker L (1974) A Platelet-Dependent Serum Factor That Stimulates the Proliferation of Arterial Smooth Muscle Cells In Vitro. Proceedings of the National Academy of Sciences of the United States of America 71: 1207-1210. [crossref]

25. Raghoebar GM, Schortinghuis J, Liem RS, Ruben JL, van der Wal JE, et al. (2005) Does platelet-rich plasma promote remodeling of autologous bone grafts used for augmentation of the maxillary sinus floor? Clinical Oral Implants Research 16: 349-356. [crossref]

26. Hamdan AA, Loty S, Isaac J, Bouchard P, Berdal A, et al. (2009) Platelet-poor plasma stimulates the proliferation but inhibits the differentiation of rat osteoblastic cells in vitro. Clin Oral Implants Res 20: 616-623. [crossref]

27. Muthukumaraswamy Arunachalam, Shaju JP, Nath Sonia (2016) Platelet Rich Fibrin in Periodontal Regeneration. Open Dent Jour 10 (Suppl 1- M4): 174-181.

\section{Citation:}

Manju Natarajan (2018) Biomaterials for Periodontal Regeneration: A Comprehensive Discussion of its Merits and Demerits. J Dent Maxillofacial Res Volume 1(2): 1-3. 